\title{
Inflammatory responses relate to distinct bronchoalveolar lavage lipidome in community-acquired pneumonia patients: a pilot study
}

Yali Zheng ${ }^{1}$, Pu Ning ${ }^{1,2}$, Qiongzhen Luo ${ }^{1}$, Yukun $\mathrm{He}^{1}$, Xu Yu${ }^{1}$, Xiaohui Liư ${ }^{3}$, Yusheng Chen ${ }^{4}$, Xiaorong Wang ${ }^{5}$, Yu Kang ${ }^{6^{*}}$ and Zhancheng Gao ${ }^{1^{*}}$ (D)

\begin{abstract}
Background: Community-acquired pneumonia (CAP) is a leading cause of morbidity and mortality worldwide. Antibiotics are losing their effectiveness due to the emerging infectious diseases, the scarcity of novel antibiotics, and the contributions of antibiotic misuse and overuse to resistance. Characterization of the lipidomic response to pneumonia and exploring the "lipidomic phenotype" can provide new insight into the underlying mechanisms of pathogenesis and potential avenues for diagnostic and therapeutic treatments.
\end{abstract}

Methods: Lipid profiles of bronchoalveolar lavage fluid (BALF) samples were generated through untargeted lipidomic profiling analysis using high-performance liquid chromatography with mass spectrometry (HPLC-MS). Principal component analysis (PCA) was applied to identify possible sources of variations among samples. Partitioning clustering analysis ( $k$-means) was employed to evaluate the existence of distinct lipidomic clusters.

Results: PCA showed that BALF lipidomes differed significantly between CAP $(n=52)$ and controls $(n=68$, including 35 healthy volunteers and 33 patients with non-infectious lung diseases); while no clear separation was found between severe CAP and non-severe CAP cases. Lactosylceramides were the most prominently elevated lipid constituent in CAP. Clustering analysis revealed three separate lipid profiles; subjects in each cluster exhibited significant differences in disease severity, incidence of hypoxemia, percentages of phagocytes in BALF, and serum concentrations of albumin and total cholesterol (all $p<0.05$ ). In addition, SM (d34:1) was negatively related to macrophage (adjusted $r=-0.462, p<0.0001)$ and PE $(18: 1 p / 20: 4)$ was positively correlated with polymorphonuclear neutrophil (PMN) percentages of BALF (adjusted $r=0.541, p<0.0001$ ). The 30-day mortality did not differ amongst three clusters $(p<0.05)$.

Conclusions: Our data suggest that specific lower airway lipid composition is related to different intensities of host inflammatory responses, and may contribute to functionally relevant shifts in disease pathogenesis in CAP individuals. These findings argue for the need to tailor therapy based on specific lipid profiles and related inflammatory status.

Trial registration: ClinicalTrials.gov (NCT03093220). Registered on 28 March 2017 (retrospectively registered).

Keywords: Community-acquired pneumonia, Lipidomic profile, Bronchoalveolar lavage, Bioactive lipid, Inflammatory response, Phagocyte

\footnotetext{
*Correspondence: zcgao@bjmu.edu.cn; kangy@big.ac.cn

${ }^{6}$ CAS Key Laboratory of Genome Sciences and Information, Beijing Institute

of Genomics, Chinese Academy of Sciences, Beijing, China

'Department of Pulmonary and Critical Care, Peking University People's

Hospital, Beijing, China

Full list of author information is available at the end of the article
}

(c) The Author(s). 2019 Open Access This article is distributed under the terms of the Creative Commons Attribution 4.0 International License (http://creativecommons.org/licenses/by/4.0/), which permits unrestricted use, distribution, and reproduction in any medium, provided you give appropriate credit to the original author(s) and the source, provide a link to the Creative Commons license, and indicate if changes were made. The Creative Commons Public Domain Dedication waiver (http://creativecommons.org/publicdomain/zero/1.0/) applies to the data made available in this article, unless otherwise stated. 


\section{Introduction}

Community-acquired pneumonia (CAP), an acute infection of the pulmonary parenchyma acquired outside of a health care setting, is a leading cause of morbidity and mortality worldwide, especially among geriatric populations [1-3]. The incidence of CAP and risk of death are linked to increasing age and the presence of comorbidities $[2,4]$. Despite the availability of effective antibiotics and improved sophisticated diagnostic techniques, CAP remains a big challenge in the era of global aging [5].

Inflammation is an essential defense part of the body's response to infection. It helps clear the invading microorganisms but can also induce host tissue damage and disease. Thus, an effective but not excessive inflammatory response may help to improve the outcome of CAP. Bioactive lipids are known to play crucial roles in the pathophysiology of inflammation, changes in their concentrations affect cell functions, often intracellular trafficking and signaling, cell adhesion, migration, and apoptosis [6]. Moreover, novel lipid mediators derived from polyunsaturated fatty acids (PUFAs), including lipoxins, resolvins, protectins, and maresins, have drawn great attention for their dual anti-inflammatory and pro-resolving effects in inflammation [7, 8]. Bioactive lipids and their derivatives could be promising therapeutic targets for CAP in the near future [9].

In a previous study, we described the serum metabolic profiles of CAP and found that the sphingolipid metabolism pathway was significantly dysregulated in pneumonia [10]. Furthermore, the serum level of sphinganine was significantly elevated in severe CAP (SCAP), indicating a potential key role for this sphingolipid in the pathogenesis of pneumonia. In order to characterize the changes in these bioactive lipids during pneumonia, we applied untargeted lipidomic profiling on bronchoalveolar lavage fluid (BALF) samples. Given that BALF has been described as a "liquid biopsy" for its diagnostic utility, this noninvasive approach represented the most effective means to uncover a lung-specific lipidomic response in vivo. We conducted principal component analysis (PCA) to identify correlations between BALF lipidomes and clinical features of patients, as well as clustering analysis to explore the existence of lipid clusters. We found specific correlations between levels of two lipid species and prevalent phagocytes in BALF, as well as three distinct lipid profiles that correlate with degree of airway inflammation. This pilot study introduces the possible utility of BALF lipidome profiles as a future aid in tailoring of CAP therapies.

\section{Materials and methods}

\section{Study populations}

We enrolled 52 CAP patients admitted to any of the four participating hospitals between March 2017 and August
2017 as part of a multicenter clinical study (ClinicalTrials. gov, NCT03093220). During this period, we recruited thirty-five healthy volunteers and thirty-three patients with non-infectious pulmonary involvement such as connective tissue disease-associated interstitial disease (CTD-ILD) as disease controls. CAP and SCAP were defined according to the standard published by America/ American Thoracic Society in 2007 [11]. Criteria for inclusion and exclusion are detailed in Fig. 1. General participant demographics, including age, gender, complications, laboratory findings, and clinical treatments, were collected using a standard form. The primary outcome was mortality follow-up at 30-days post-bronchoscopy. Individuals who aged over 65 were defined as the elderly. The ethical committee of Peking University People's Hospital approved the research. All subjects provided written informed consent prior to the collection of any data.

\section{BALF sample collection and preservation}

Bronchoscopy was performed within $72 \mathrm{~h}$ after hospital admission. Clinicians determined the necessity and feasibility of bronchoscopy individually. Briefly, two $50 \mathrm{~mL}$ aliquots $(100 \mathrm{~mL}$ total) of sterile normal saline were instilled into the diseased region according to CT scan results (for CAP patients), or into the right middle lobe or lingual (for controls). Aliquots were then retrieved by gentle suctioning through the suction port of the bronchoscope. No suction was performed before sample collection. Total and differential cell counts, etiological examination, and protein concentration of BALF samples were analyzed respectively at the time of collection in local labs. Protein in the BALF samples was measured with the bicinchoninic acid (BCA) assay (Pierce, Thermo Fisher Scientific, Rockford, IL USA). The rest BALF samples were clarified by centrifugation at $10,000 \times \mathrm{g}$ for $10 \mathrm{~min}$ at $4{ }^{\circ} \mathrm{C}$ and the supernatants and precipitates were separated and frozen ($80^{\circ} \mathrm{C}$ ) until the time of assay.

\section{Untargeted lipidomic profiling analysis based on HPLC- MS \\ BALF sample preprocessing}

BALF samples were thawed on ice at the time of assay. The sample volume used in high-performance liquid chromatography-mass spectrometry (HPLC-MS) analysis was normalized by its protein concentration to get an equal mass for all samples [12]. The equation was as follows: Sample volume $(\mu \mathrm{L})=$ a constant mass $(\mathrm{g}) / \mathrm{BALF}$ protein concentration $(\mathrm{g} / \mathrm{L}) \times 1000$. A methyl tert-butyl ether (MTBE)-based extraction protocol [13] was used. For deproteinization, samples were freeze-dried (CentriVap $^{\oplus}$ ) and then combined with $200 \mu \mathrm{L}$ of pre-chilled $75 \%$ methanol containing $0.5 \mu \mathrm{g} / \mathrm{mL}$ L-Tryptophan-(indole-d5) which served as an internal control. The sample was combined with $500 \mu \mathrm{L}$ of MTBE and vortexed. Then the 


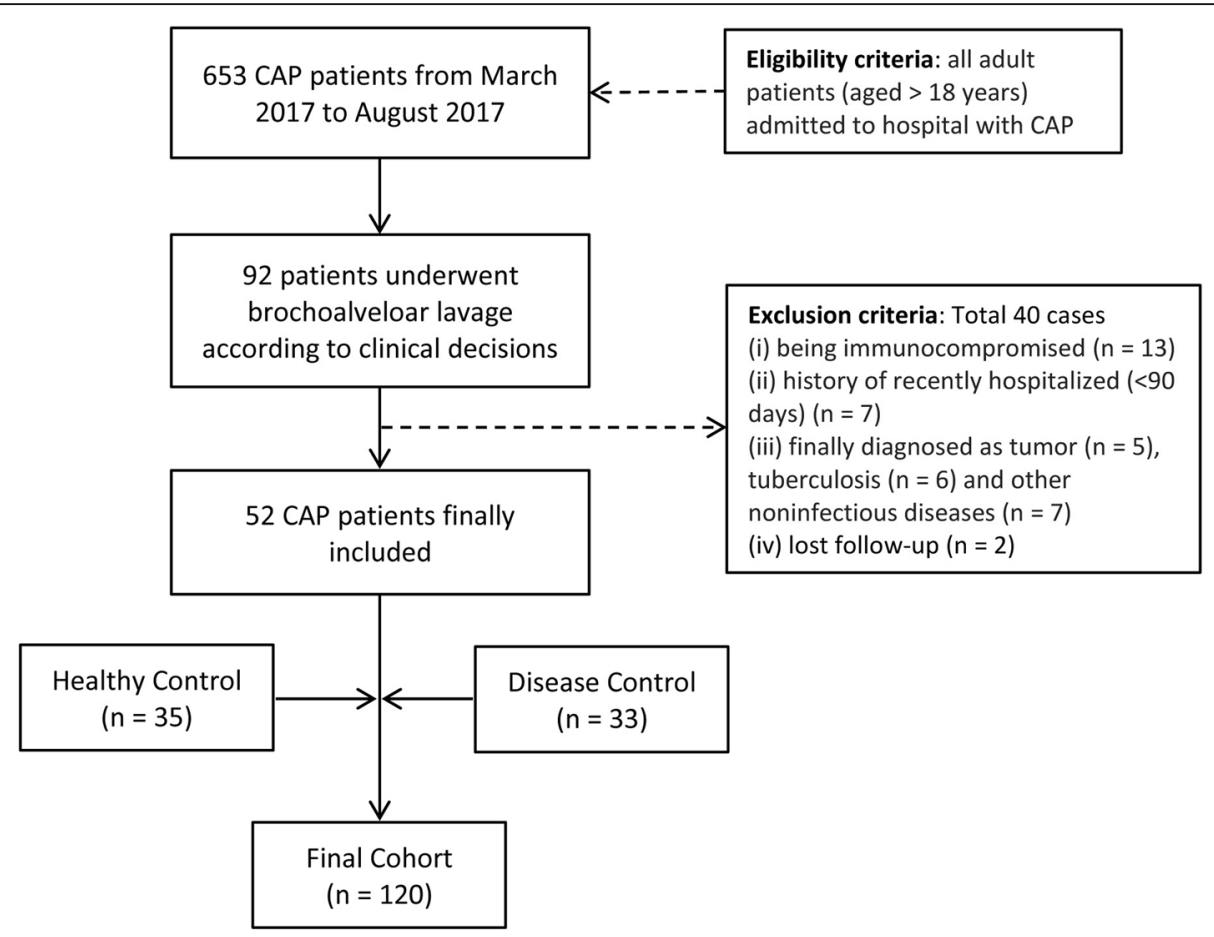

Fig. 1 Flowchart of study enrollment

mixtures were incubated for $1 \mathrm{~h}$ at room temperature. $125 \mu \mathrm{L}$ of HPLC-grade water was added, then centrifuged $\left(15 \mathrm{~min}\right.$ at $\left.14,000 \times \mathrm{g}, 4^{\circ} \mathrm{C}\right)$. The upper non-polar fraction was transferred to a new $1.8 \mathrm{~mL}$ Eppendorf tube, then freeze-dried and stored at $-80^{\circ} \mathrm{C}$ until untargeted LC-MS analysis. Quality control (QC) samples were prepared by pooling $20 \mu \mathrm{L}$ aliquots from each sample and extracted as above.

Untargeted HPLC-MS analysis and compounds identification HPLC-MS analysis was performed using a Cortecs C18 column $(2.1 \times 100 \mathrm{~mm}$, Waters $)$ on an Ultimate 3000 UHPLC (Dionex) system coupled with Q Exactive (Orbitrap) mass spectrometer (Thermo Fisher, CA). The dried samples were reconstituted in chloroform:methanol (2:1 $v / \mathrm{v}$ ) and transferred to an autosampler vial for analysis. Before experimental sample analyses, six QC samples were injected to stabilize the instrument. All samples were processed in random order and were assigned to an HPLC-MS run in random order using a computerized algorithm, with a QC sample between every 10 experimental samples. Detailed parameters for the untargeted lipid analyses were set following the protocols of our previously reported study [14] and described in the Additional file 1: Supplementary Method. Data-dependent MS/MS acquisition (DDA) of all samples was analyzed using TraceFinderTM (Thermo, CA). Lipids were assigned using an in-house lipid database in "screening" mode and qualified in "quan" mode. Lipids were identified based on matching precursor and characteristic fragment masses. Five ppm and $10 \mathrm{ppm}$ mass tolerance was used for precursor and fragment, respectively. Only the lipids with chromatographic area $>5 \times 10^{6}$ were considered as confident identification. A 0.25 min retention time shift was allowed for quantitation.

\section{HPLC-MS data analysis workflow Data preprocessing}

First, a lipid was kept if it had a non-zero value for at least $80 \%$ in the samples of any one group (CAP or controls) $[15,16]$. Second, missing values were replaced by a small value (half of the minimum positive value in the original data), assuming that most missing values are caused by low abundance compounds (i.e., below the detection limit) [16, 17]. Afterward, to reduce the large differences between the total amounts of compounds among the diverse samples and to increase the contribution of lower concentration metabolites in the generated models, data were normalized to the constant sum and then auto scaled [18] (mean-centered and divided by the standard deviation of each variable) using MetaboAnalyst 4.0 [19]. The normalized data were used for downstream analysis.

\section{Data analysis}

Unsupervised principal component analysis (PCA) was performed using SIMCA-P software version 14.0 
(Umetrics, Umea, Sweden) in order to find distribution trends and possible sources of variation among samples. Subsequently, to evaluate if the host-lipidome in BALF could be partitioned into clusters with distinct lipidomic phenotypes, $k$-means partitional clustering [20] was employed based on the lipid profiles of all subjects using MetaboAnalyst 4.0. An optimal number of clusters $k$ is the one that maximizes the average silhouette over a range of possible values for $k$. The elbow method [21] was used to determine the optimal number of clusters using the $\mathrm{R}$ package "NbClust" [22]. The idea of the elbow method is to run $k$-means clustering on the dataset for a range of values of $k$, and for each value of $k$ calculate the sum of squared errors (SSE). For correlation studies, the two-tailed Spearman test was used to calculate correlation significance. Multiple linear regression (MLR) analysis was then conducted using a stepwise method to adjust multi-colinearity inherent in lipidomic data.

\section{Statistical analysis}

All categorical variables are presented as numbers (percentages), parametric continuous variables are presented as mean $\pm \mathrm{SD}$, and nonparametric continuous variables are presented as median and interquartile ranges (25th and 75th percentiles). Student's t-test or analysis of variance (ANOVA) with post-hoc Tukey HSD test were used to analyze continuous parametric data, whereas continuous nonparametric data were analyzed using Mann-Whitney U or a Kruskal-Wallis test. All categorical data were analyzed using chi-square or Fisher's exact test. Analyses were performed in SPSS Statistics (version 22.0) or MetaboAnalyst 4.0 [19]. A nominal $p$-value of less than 0.05 was considered to be of statistical significance for clinical data. Benjamini-Hochberg (BH) adjusted p-value of less than 0.05 was defined as significant for HPLC-MS data.

\section{Results}

\section{Lipid profiles of human BALF}

BALF lipid profiles of 120 subjects were generated through untargeted lipidomic profiling analysis using HPLC-MS. The final study population consisted of 52 patients with CAP, 35 healthy individuals and 33 patients with connective tissue disease-associated interstitial lung disease (CTD-ILD) as disease controls (Fig. 1). As indicated in Table 1, there was a range of etiologies of CAP including bacteria, virus, and fungus, which was typical for a heterogeneous CAP patient population. Additional demographic data about these patients are detailed in Table 1.

Overall, mass spectrometry detected 150 lipid species in these samples, 65 in positive and 108 in negative electrospray ionization (ESI) mode. The lipids were categorized into 5 lipid classes: fatty acids (FA), neutral lipids, sphingolipids, phospholipids and acylcarnitines (Fig. 2a,
Additional file 2: Table S1). Acylcarnitines, sphingolipid, and neural Lipid were more effectively detected in positive ion mode; while FA and phospholipids were more effectively detected in negative ion mode. In BALF samples, FAs contributed $57.15 \%$ to the total lipid signal; followed by neural lipids (25.65\%), sphingolipids (10.23\%), and phospholipids (6.94\%). The top 4 dominant lipid subclasses comprised over $90 \%$ of the total lipid signal (Fig. 2b, Additional file 2: Table S1), including saturated FA (SFA, 54.96\%), triglyceride (TG, 23.77\%), sphingomyelin (SM, 7.91\%), and phosphatidylcholine (PC, 4.26\%).

\section{Lipidomic alterations in CAP}

Kruskal-Wallis test identified ten lipid subclasses (Table 2) that were significantly different in SCAP patients, compared to controls (adjusted $p$-value $<0.05$ ). Significantly increased BALF level of lactosylceramide (CerG2, > 10-fold in relative abundance), monounsaturated FA (MUFA, > 2-fold), polyunsaturated FA (PUFA, > 2-fold), phosphatidylethanolamine ( $\mathrm{PE},>2$-fold), and diglyceride (DG, 2-fold) were observed in SCAP patients, while sphingosine (So), phosphatidylglycerol (PG), lysophosphatidylcholine (LPC), lysophosphatidylethanolamine (LPE), and lysophosphatidylglycerol (LPG) were notably decreased $\sim 0.5$-fold. No significantly differences in lipid subclasses were observed between the SCAP and the NSCAP groups.

All identified lipids were subjected to PCA in SIMCA 14.1 to explore the major effects that potentially drive the differences in lipid profiles in CAP patients. The PCA resulted in a ten-component model, $\mathrm{R}^{\mathrm{X}} \mathrm{X}_{(\mathrm{cum})}=$ 0.871 and Q2 (cum) $=0.76$. As shown in Fig. 3a, samples in the control group clustered tightly, while samples in the CAP group were distributed diffusely, thus revealing high heterogeneity in the lipids that accompany this disease. Classifications based on disease severity (SCAP vs NSCAP, Fig. 3b), age (adult CAP vs elder CAP, Fig. 3c), gender (male CAP vs female CAP, Fig. 3d), and causative pathogens (viral, bacterial, fungal, or mixed infection, Fig. 3e) revealed indistinct separation trends, suggesting that individually, the major clinical-demographic features do not contribute strong effects to the clustering patterns of these BALF lipids.

Thirty-three lipid species were identified (32 higher and 1 lower, Additional file 2: Table S2) that displayed differential relative abundance amongst SCAP, NSCAP, and Control (ANOVA with Turkey host HSD test, FDR $<0.05$ ), consisting of 3 sphingolipid, 6 FA, and 24 phospholipid species. Overall, most of the significantly different lipids were elevated in SCAP subjects (including SM, FA, phosphatidylcholine (PC), PE, and phosphatidylinositol (PI) species). Only palmitic acid (FA 16:0), which comprised $25.96 \%$ of the total lipid signal, 
Table 1 Demographical and Clinical features of included subjects

\begin{tabular}{|c|c|c|c|c|}
\hline & $\operatorname{SCAP}(n=21)$ & $\operatorname{NSCAP}(n=31)$ & Controls $(n=68)$ & $p$-value \\
\hline Age & $58.48 \pm 17.37$ & $49.53 \pm 23.07$ & $53.43 \pm 12.45$ & 0.164 \\
\hline Gender, n, (\% male) & $16(76.2 \%)$ & $17(54.8 \%)$ & $20(29.4 \%)$ & $<0.0005^{\mathrm{a}, \mathrm{b}}$ \\
\hline Ever smokers, n (\%) & $4(19.0 \%)$ & $4(12.9 \%)$ & $2(2.9 \%)$ & 0.019 \\
\hline Current Smokers, n (\%) & $6(28.6 \%)$ & $5(16.1 \%)$ & $5(7.4 \%)$ & 0.035 \\
\hline \multicolumn{5}{|l|}{ Comorbidities } \\
\hline Diabetes Mellitus, n (\%) & $5(23.8 \%)$ & $3(9.7 \%)$ & $11(16.2 \%)$ & 0.398 \\
\hline Hypertension, n (\%) & $6(28.6 \%)$ & $10(32.3 \%)$ & $21(30.9 \%)$ & 1.0 \\
\hline Hyperlipidemia, n (\%) & $2(9.5 \%)$ & $9(29.0 \%)$ & $8(11.8 \%)$ & 0.089 \\
\hline Coronary Heart Disease, n (\%) & $4(19.0 \%)$ & $3(9.7 \%)$ & $8(11.8 \%)$ & 0.643 \\
\hline \multicolumn{5}{|l|}{ Laboratory findings of BALF } \\
\hline Total cell counts $\left(\times 10^{6}\right.$ cells $)$ & $0.2(0.18-0.2)$ & $0.2(0.18-0.35)$ & $0.2(0.13-0.29)$ & 0.704 \\
\hline PMN percentages (\%) & $41.0(2.0-65.0)$ & $4.5(1.5-28.0)$ & $1.5(1.0-4.5)$ & $<0.0005^{\mathrm{a}, \mathrm{b}}$ \\
\hline Macrophage percentages (\%) & $35.0(14.0-58.0)$ & $50.0(32.0-70.5)$ & $72.25(43.5-88.0)$ & $<0.0005^{\mathrm{a}, \mathrm{b}}$ \\
\hline Lymphocyte percentages (\%) & $20.0(13.0-27.0)$ & $19.75(10.0-42.0)$ & $21.5(9.25-41.0)$ & 0.948 \\
\hline Eosinophil percentages (\%) & $0(0-0)$ & $0(0-1)$ & $0(0-0.75)$ & 0.320 \\
\hline Albumen concentration (g/L) & $1.45(0.89-2.36)$ & $0.43(0.10-1.92)$ & $0.17(0.08-0.27)$ & $<0.0005^{\mathrm{a}, \mathrm{b}, \mathrm{c}}$ \\
\hline \multicolumn{5}{|l|}{ Detected pathogen } \\
\hline Bacteria & $5(23.8 \%)$ & $0(0)$ & NA & 0.017 \\
\hline Atypical pathogen & $5(23.8 \%)$ & $9(29.0 \%)$ & NA & 0.677 \\
\hline Virus & $6(28.6 \%)$ & $11(35.5 \%)$ & NA & 0.602 \\
\hline Fungus & $2(9.5 \%)$ & $2(6.5 \%)$ & NA & 0.903 \\
\hline Unknown & $7(33.3 \%)$ & $15(48.4 \%)$ & NA & 0.281 \\
\hline
\end{tabular}

Abbreviations: BALF bronchoalvolar lavage, $P M N$ polymorphonuclear leukocyte, NA not available. Data are presented as $\mathrm{n}(\%)$ for categorical data, mean ( \pm SD) for parametrically distributed data, or median (interquartile range) for nonparametrically distributed data. Statistically significant differences in variables amongst three groups were calculated using one-way ANOVA with post-hoc Turkey HSD test or Kruskal-Wallis $\mathrm{H}$ test for continuous data; and Fisher's exact test with a Bonferroni correction for categorical data. ${ }^{a}$ statistically significance exists between SCAP and Control; ${ }^{b}$ statistically significance exists between NSCAP and Control; ${ }^{c}$ statistically significance exists between SCAP and NSCAP

was significantly decreased in SCAP. Few lipid species were differentially expressed between SCAP and NSCAP, including SM (d34:1), PE (16:0p/20:4), and PC (18:0/ 20:3). Subsequently, to determine the predictive ability of these differential lipids as biomarkers for SCAP, we applied receiver operating characteristic (ROC) analysis and compared their areas under the curve (AUC). As shown in Additional file 3: Figure S1, FA (24:0), FA (20:1), FA (18:1), and FA (16:1) exhibited good performances in discriminating SCAP from NSCAP patients $(\mathrm{AUC}=0.747, \mathrm{AUC}=0.737, \mathrm{AUC}=0.757$, and $\mathrm{AUC}=$ 0.747 , respectively).

\section{Unsupervised clustering revealed three distinct lipidomic clusters (LCluster) correlated with different inflammatory responses and disease severity}

To evaluate whether BALF samples from all cohorts could be partitioned into clusters with distinct lipidomic phenotypes, we performed the $k$-means algorithm and the $k$ number was determined by the elbow method (Additional file 3: Figure S2). This approach yielded three separate lipid clusters (LClusters) (Fig. 4a). Clinical and laboratory characteristics were compared in detail amongst the three clusters (Table 3): LClus1, LClus2, and LClus3. The percentages of polymorphonuclear leukocytes (PMN) in BALF significantly differed among the three clusters, with the highest value in LClus1 and the lowest in LClus3 (Fisher's exact test, $p<0.0001$, Fig. 4d); while the percentages of macrophage revealed an opposite tendency (Fig. 4e). Since PMN infiltration plays a central role in inflammation and is a major cause of tissue damage, we stratified our subjects into high(LClus1), medium- (LClus2), and low- (LClus3) inflammatory response groups. Patients in LClus1 were characterized by lower serum concentrations of albumin (ALB) and total cholesterol (TC) (Fisher's exact test, $p<0.01$ ). The incidence of hypoxemia was significantly higher in LClus1 $(6 / 6,100 \%)$ than in the other two groups (17.57\% in LClus 2 and $7.5 \%$ in LClus $3, p=0.008$ and 0.005 , respectively). Half of the patients in LClus1 received invasive positive pressure ventilation (IPPV) therapy (Fisher's exact test, $p=0.022$ ), which is the highest 


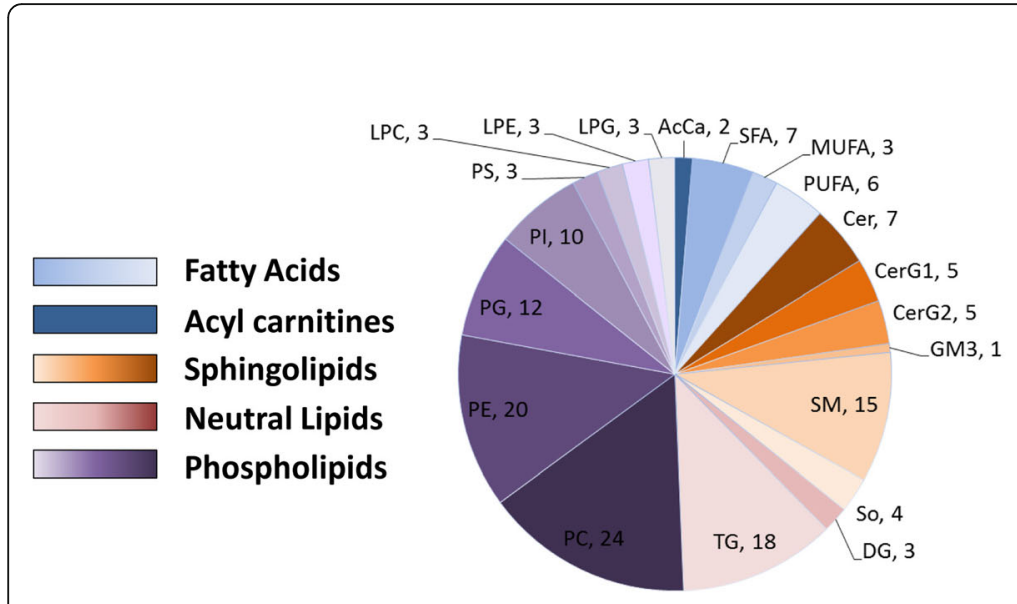

a Lipid subclasses, Number of identifications



b Lipid subclasses, Percentage of total lipidome

Fig. 2 Overview of bronchoalveolar lavage fluid (BALF) lipidome.

a A total of 150 lipid species are detected in BALF samples of community-acquired pneumonia (CAP) and Controls. The lipids are categorized into 5 lipid classes: fatty acids (light blue), acylcarnitines (dark blue), sphingolipids (orange), neutral lipids (pink), and phospholipids (purple). b The compositions of total BALF lipid signal. Proportions of each lipid subclass are calculated by normalizing to total lipid intensities

Table 2 Comparisons of lipid subclasses between CAP and controls

\begin{tabular}{|c|c|c|c|c|c|c|c|}
\hline \multirow[t]{2}{*}{ Lipid Class } & \multirow{2}{*}{$\begin{array}{l}\text { Lipid } \\
\text { Sub- } \\
\text { Class }\end{array}$} & \multirow[t]{2}{*}{ Adduct } & \multirow{2}{*}{$\begin{array}{l}\% \text { of } \\
\text { the } \\
\text { total } \\
\text { lipid } \\
\text { signals }\end{array}$} & \multicolumn{3}{|l|}{ Fold change } & \multirow{2}{*}{$\begin{array}{l}\text { Kruskal- } \\
\text { Wallis } \\
\text { adjusted } \\
p \text {-value }\end{array}$} \\
\hline & & & & SCAP/Control & NSCAP/ Control & SCAP/NSCAP & \\
\hline Acylcarnitines & $\mathrm{AcCa}$ & $+\mathrm{H}$ & $0.06 \%$ & 0.48 & 0.75 & 0.63 & 0.078 \\
\hline \multirow[t]{3}{*}{ Fatty acids } & SFA & $-H$ & $54.96 \%$ & 0.93 & 0.99 & 0.94 & 0.14 \\
\hline & MUFA & $-H$ & $1.35 \%$ & $2.13^{* * *}$ & $1.13^{* *}$ & 1.92 & $<0.0005$ \\
\hline & PUFA & $-H$ & $0.85 \%$ & $2.50^{*}$ & $1.33^{*}$ & 1.92 & 0.004 \\
\hline \multirow[t]{6}{*}{ Sphingolipids } & Cer & $+\mathrm{H}$ & $2.16 \%$ & 1.09 & 1.41 & 0.81 & 0.95 \\
\hline & CerG1 & $+\mathrm{H}$ & $0.32 \%$ & 1.13 & 1.46 & 0.82 & 0.482 \\
\hline & CerG2 & $+\mathrm{H}$ & $0.25 \%$ & $16.36^{* * *}$ & $13.51^{* * *}$ & 1.64 & $<0.0005$ \\
\hline & GM3 & $+\mathrm{H}$ & $0.01 \%$ & 0.98 & 1.16 & 0.88 & 0.125 \\
\hline & SM & $+\mathrm{H}$ & $7.91 \%$ & 1.11 & 1.06 & 1.06 & 0.792 \\
\hline & So & $+\mathrm{H}$ & $0.81 \%$ & $0.44^{* * *}$ & $0.65^{* *}$ & 0.67 & $<0.0005$ \\
\hline \multirow[t]{2}{*}{ Neutral lipids } & DG & $+\mathrm{NH} 4$ & $1.88 \%$ & $1.96^{*}$ & 1.96 & 0.94 & 0.031 \\
\hline & TG & $+\mathrm{NH} 4$ & $23.77 \%$ & 0.92 & 0.91 & 1.00 & 0.222 \\
\hline \multirow[t]{8}{*}{ Phospholipids } & $P C$ & $+\mathrm{CH} 3 \mathrm{COO}$ & $4.26 \%$ & 1.36 & 1.01 & 1.36 & 0.81 \\
\hline & $P E$ & $-H$ & $0.72 \%$ & $2.14^{* * * *}$ & $1.43^{*}$ & 1.60 & $<0.0005$ \\
\hline & $P G$ & $-H$ & $0.77 \%$ & $0.67^{*}$ & 0.87 & 0.76 & 0.019 \\
\hline & $\mathrm{Pl}$ & $-H$ & $0.45 \%$ & 1.65 & 0.90 & 1.84 & 0.110 \\
\hline & PS & $-H$ & $0.09 \%$ & 1.69 & 1.50 & 1.20 & 0.034 \\
\hline & LPC & $+\mathrm{H}$ & $0.55 \%$ & $0.47^{* *}$ & 0.71 & 0.70 & 0.002 \\
\hline & LPE & $+\mathrm{H}$ & $0.08 \%$ & $0.49^{*}$ & 0.76 & 0.70 & 0.014 \\
\hline & LPG & $-H$ & $0.01 \%$ & $0.41^{* * *}$ & 0.72 & 0.58 & $<0.0005$ \\
\hline
\end{tabular}

The relative abundances of lipid subclasses were calculated from the sum of lipid species that classified to the same subclass. The * depicts a statistically significant difference. ${ }^{*} p<0.05 ;{ }^{* *} p<0.01 ;{ }^{* *} p<0.001$ 


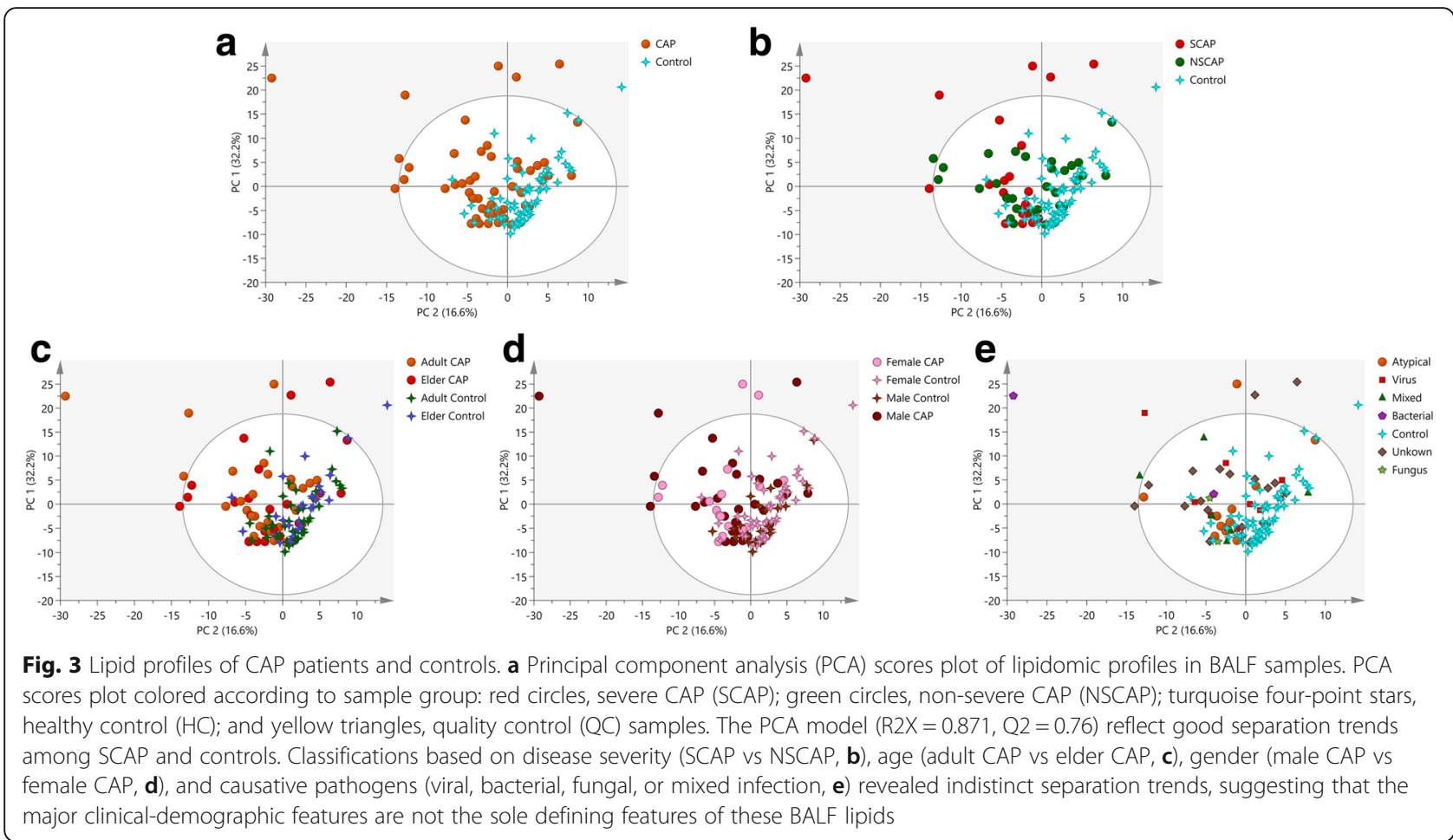

ratio of three clusters, although without statistical significance in the following pairwise comparisons. In addition, patients in LClus1 were predicted to have the highest mortality (defined as Pneumonia Severity Index (PSI) class $=5$, Fig. 4c). Based on the above findings, we presumed that the different intensities of inflammatory responses were also associated with diverse disease severity degrees. Goodman's \& Kruskal's Gamma test showed statistically significant positive correlations between the inflammatory response rankings (high-, medium-, and low-) and the degree of disease severity, which were assessed using the following severity scoring systems: PSI $(p=0.045, \mathrm{G}=0.429)$, CURB-65 $(p=0.034$, $\mathrm{G}=0.446)$ and APACHE II $(p=0.007, \mathrm{G}=0.565)$, respectively. However, patients in the high- and the medium- response groups both revealed high mortality rate $(16.7 \%$ vs $15.2 \%$, Fisher's exact test, $p>0.05)$. No difference was observed in the spectrum of pathogen amongst clusters.

\section{Distinct lipid profiles of the three LClusters}

We originally hypothesized that variation in the lipid compositions of each of the three clusters was related to differences in clinical characteristics among patients. However, the high- (LClus1) and the medium- (LClus2) inflammatory response groups had distinct alterations of BALF lipidomes compared to the low-inflammatory response group (LClus3) (Table 4, Fig. 4b). LClus1 was characterized by the highest mean relative abundance of unsaturated FA (including MUFA and PUFA) and CerG2 classes. In contrast, LClus2 exhibited the highest level of SFA and TG classes, and the lowest level of sphingolipids (SM and GM3 classes) and phospholipids (PC, PE, PG, PI, and PS classes). Subsequently, we identified 41 lipid species (Additional file 2: Table S3) that differed amongst all three clusters (ANOVA with Tukey host HSD test, FDR adjusted $p$-value $<0.05)$. In accordance with the results of lipid class analysis, we observed significant abundant n-3 PUFA (FA 18:3, $\alpha$-linolenic acid) in LClus1. Two SFA species (FA 16:0 and FA 18:0, comprising $53.62 \%$ of the total lipid signal) and 3 TG species were notably increased, while $7 \mathrm{SM}, 12 \mathrm{PC}, 8 \mathrm{PE}$, 1 PG, 5 PI, and 2 PS species were significantly decreased in LClus2. Generally, the differential accumulation of lipid species revealed opposite trends in the changes in BALF lipid composition, compared to the low response group (LClus3). These data suggest that different underlying mechanisms may govern lipid regulation in response to the degree of inflammation during CAP.

\section{Correlations between lipids and clinical indices}

Spearman rank correlation analysis was applied to detect whether the differentially accumulating lipids of clusters were correlated with clinical parameters, including percentages of macrophages and neutrophils in BALF, serum ALB, and serum TC levels. When a correlation between lipid levels and clinical parameters was identified, multiple linear regression (MLR) analysis was then 

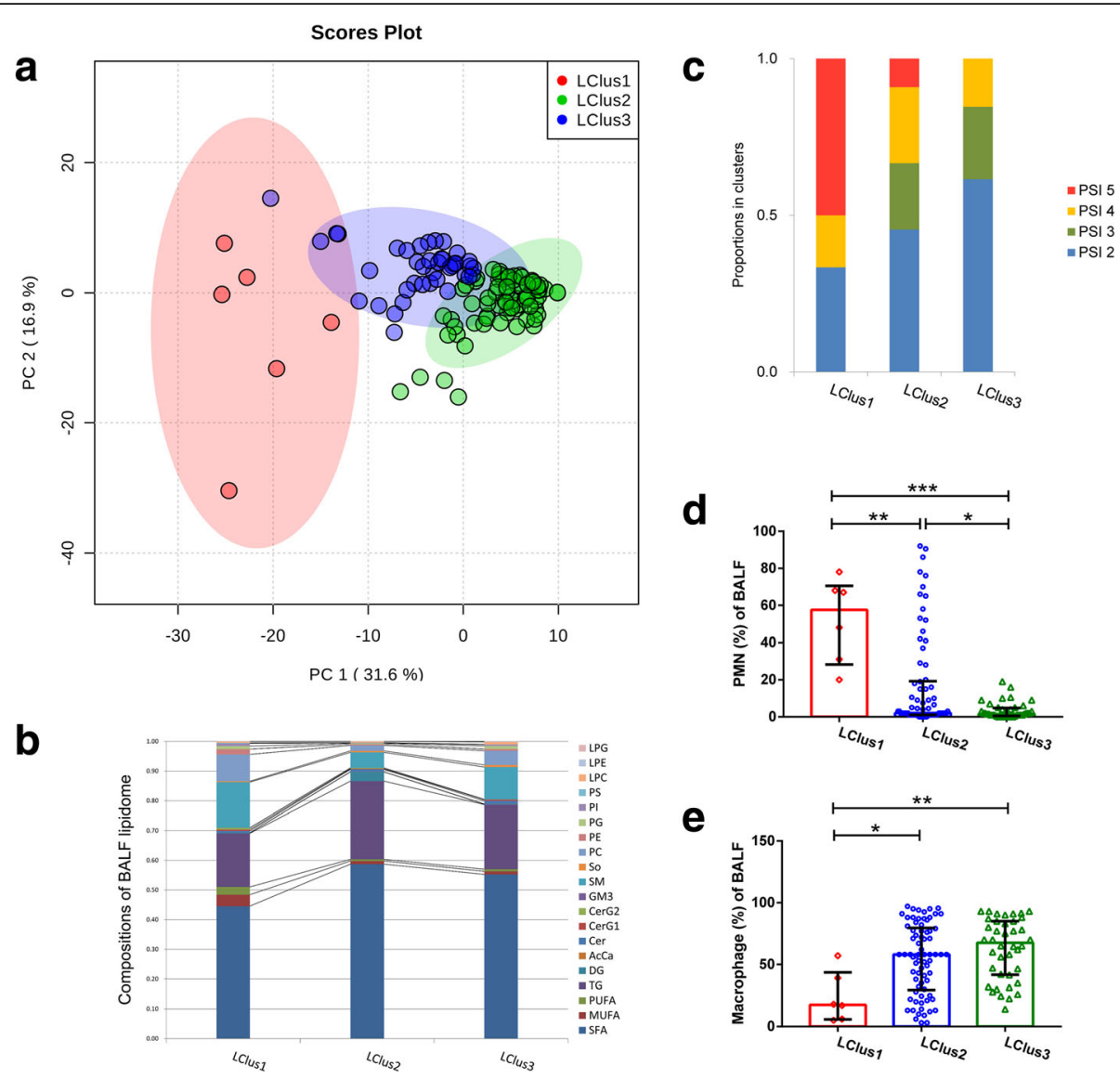

Fig. 4 Panel a: PCA scores plot of three distinct lipid clusters (LCluster). Red, LClus1; blue, LClus2; green, LClus3. Panel b: Distinct compositions of lipid subclasses amongst three clusters. Panel $\mathbf{c}$ : The distributions of CAP patients with different PSI classes amongst three clusters. PSI 2 (blue section), 51-70 points; PSI 3 (green section), 71-90 points; PSI 4 (yellow section), 91-130 points; and PSI 5 (red section), 131-395 points. Panel d-e: Comparisons of macrophage percentages (d) and PMN percentages of BALF (e) amongst the three clusters. LClus1 exhibits the highest percentage of polymorphonuclear leukocytes (PMNs) and the lowest percentage of macrophages in BALF

conducted using a stepwise method to adjust for the multi-collinearity inherent in lipidomic data (Additional file 2: Table S4, Fig. 5). Finally we identified that SM (d34:1) was negatively related to macrophage percentages in BALF (adjusted $r=-0.462, p<0.0001$ ) and PE (18:1p/20:4) was positively correlated with $\mathrm{PMN}$ percentages of BALF (adjusted $r=0.541, p<0.0001$ ). No significant correlations were observed between differential lipid species and ALB or TC, indicating that shifts in the BALF lipidome are related to a local rather than a systemic inflammatory response.

\section{Discussion}

In the current study, we characterized the BALF lipidomes of 120 subjects including 52 CAP patients and 68 controls. We found that in BALF samples from CAP patients, the levels of unsaturated FA, CerG2, and PE classes were increased compared to controls, while the So class was decreased. Using classifications based on clinical-demographic features (regardless of disease severity, age, gender, or pathogen types) with principal component analysis revealed no clear patterns of separation for distinguishing lipid profiles that correlated with any of the clinical features. However, cluster analysis identified three distinct lipid clusters; subjects in different clusters exhibited significant differences in disease severity, the incidence of hypoxemia, the percentages of PMNs and macrophages in BALF, and the serum concentrations of albumin and total cholesterol. We also identified individual lipids at the molecular level (SM $\mathrm{d} 34: 1$ and PE 18:1p/20:4) that significantly correlated with the phagocytes (PMNs and macrophages) in BALF. Our findings thus suggest that the specific lipid composition in the lower airway may relate to the intensity of the host inflammatory response, rather than clinical and demographic differences, and may contribute to functionally relevant shifts in CAP disease pathogenesis. Based on their appearance in consistent ratios across severely inflamed cases of CAP, SM d34:1 and PE 18:1p/ 20:4 may serve as reliable diagnostic markers for 
Table 3 Demographical and clinical features of all subjects in three lipid clusters

\begin{tabular}{|c|c|c|c|c|}
\hline & $\begin{array}{l}\text { LClus1 } \\
(n=6)\end{array}$ & $\begin{array}{l}\text { LClus2 } \\
(n=74)\end{array}$ & $\begin{array}{l}\text { LClus3 } \\
(n=40)\end{array}$ & $p$-value \\
\hline \multicolumn{5}{|l|}{ Cluster composition } \\
\hline CAP patients, n (\%) & $6(100 \%)$ & $33(44.6 \%)$ & $13(32.5 \%)$ & $0.005^{\mathrm{a}, \mathrm{b}}$ \\
\hline SCAP patients, n (\%) & $6(100 \%)$ & $14(18.9 \%)$ & $1(2.5 \%)$ & $<0.0005^{\mathrm{a}, \mathrm{b}, \mathrm{c}}$ \\
\hline \multicolumn{5}{|l|}{ Demographics } \\
\hline Age (years) & $55.17 \pm 16.13$ & $53.49 \pm 16.88$ & $52.77 \pm 16.78$ & 0.935 \\
\hline Gender, n, (\% male) & $4(66.7 \%)$ & $35(47.3 \%)$ & $14(35.0 \%)$ & 0.243 \\
\hline Ever smokers, n (\%) & $1(16.7 \%)$ & $6(8.1 \%)$ & $3(7.5 \%)$ & 0.600 \\
\hline Current smokers, n (\%) & $1(16.7 \%)$ & $12(16.2 \%)$ & $3(7.5 \%)$ & 0.390 \\
\hline \multicolumn{5}{|l|}{ Underlying Diseases } \\
\hline Diabetes Mellitus, n (\%) & $2(33.3 \%)$ & $12(16.2 \%)$ & $5(12.5 \%)$ & 0.376 \\
\hline Hypertension, n (\%) & $1(16.7 \%)$ & $25(33.8 \%)$ & $11(27.5 \%)$ & 0.661 \\
\hline Hyperlipidemia, n (\%) & 0 & $13(17.6 \%)$ & $6(15.0 \%)$ & 0.692 \\
\hline Coronary Heart Disease, n (\%) & $2(33.3 \%)$ & $9(12.2 \%)$ & $4(10.0 \%)$ & 0.281 \\
\hline \multicolumn{5}{|l|}{ Laboratory Findings } \\
\hline \multicolumn{5}{|l|}{ Peripheral blood related } \\
\hline BUN (mmol/L) & $4.4(1-27)$ & $4.4(1-25)$ & $4.4 \pm 1.5$ & 0.323 \\
\hline $\mathrm{Cr}(\mu \mathrm{mol} / \mathrm{L})$ & $86.5(30-448)$ & $60(30-237)$ & $61.9 \pm 18.4$ & 0.345 \\
\hline $\operatorname{ALT}(U / L)$ & $24.5(12.0-77.5)$ & $25.5(13.3-44.5)$ & $28.0(18.0-41.0)$ & 0.958 \\
\hline AST (U/L) & $30.5(14.8-248.5)$ & $25(18.0-32.0)$ & $28.0(21.0-43.0)$ & 0.422 \\
\hline CK (U/L) & $41.5(19.0-540.0)$ & $58.5(43.3-94.8)$ & $84(48.0-116.0)$ & 0.765 \\
\hline ALB $(g / L)$ & $25.4 \pm 5.2$ & $35.3 \pm 6.7$ & $35.8 \pm 5.5$ & $0.006^{\mathrm{a}, \mathrm{b}}$ \\
\hline Glucose (mmol/L) & $9.4 \pm 4.5$ & $5.1(4.7-6.2)$ & $4.8(4.5-5.7)$ & 0.086 \\
\hline $\mathrm{TC}(\mathrm{mmol} / \mathrm{L})$ & $2.8 \pm 1.0$ & $3.8(3.7-4.7)$ & $4.8 \pm 1.3$ & $<0.0005^{\mathrm{a}, \mathrm{b}, \mathrm{c}}$ \\
\hline TG (mmol/L) & $1.0(0.7-2.8)$ & $1.2(0.9-1.6)$ & $1.8 \pm 1.0$ & 0.166 \\
\hline WBC $\left(\times 10^{9} / L\right)$ & $11.3(6.3-17.0)$ & $6.1(5.1-8.4)$ & $6.7 \pm 2.1$ & 0.241 \\
\hline Neutrophils $\left(\times 10^{9} / \mathrm{L}\right)$ & $8.9 \pm 4.7$ & $4.0(3.1-6.0)$ & $4.5 \pm 1.7$ & 0.105 \\
\hline Lymphocytes $\left(\times 10^{9} / L\right)$ & $1.0 \pm 0.4$ & $1.3 \pm 0.6$ & $1.5 \pm 0.9$ & 0.08 \\
\hline NLR & $11.5 \pm 9.7$ & $2.9(2.2-5.3)$ & $3.9 \pm 2.6$ & 0.092 \\
\hline \multicolumn{5}{|l|}{ BALF related } \\
\hline Total cell counts $\left(\times 10^{6}\right.$ cells $)$ & $0.48(0.18-0.74)$ & $0.2(0.16-0.29)$ & $0.2(0.14-0.25)$ & 0.182 \\
\hline PMN percentages (\%) & $57.5(28.3-70.5)$ & $2(1-19.3)$ & $1.5(0-4.0)$ & $<0.0005^{\mathrm{a}, \mathrm{b}, \mathrm{c}}$ \\
\hline Macrophage percentages (\%) & $23.7 \pm 20.4$ & $54.7 \pm 28.2$ & $63.9 \pm 24.0$ & $0.006^{\mathrm{a}, \mathrm{b}}$ \\
\hline Lymphocyte percentages (\%) & $14.5(9.8-38.0)$ & $20(9.0-37.0)$ & $24(13.0-48.0)$ & 0.195 \\
\hline Eosinophil percentages (\%) & $0(0-1)$ & $0(0-1)$ & $0(0-0.5)$ & 0.979 \\
\hline Albumen concentration $(\mathrm{g} / \mathrm{L})$ & $4.01(0.87-6.05)$ & $0.35(0.17-1.16)$ & $0.08(0.06-0.22)$ & $<0.0005^{\mathrm{a}, \mathrm{b}, \mathrm{c}}$ \\
\hline \multicolumn{5}{|l|}{ Inflammatory markers ${ }^{\mathrm{d}}$} \\
\hline$P C T(\mu g / L)$ & $17.9 \pm 26.0$ & $0.17(0.05-0.37)$ & $0.17(0.11-0.21)$ & $0.008^{\mathrm{a}, \mathrm{b}}$ \\
\hline $\mathrm{CRP}(\mathrm{mg} / \mathrm{L})$ & $83.7 \pm 65.3$ & $43.82(13.8-117.0)$ & $43.82(11.7-88.4)$ & 0.611 \\
\hline ESR $(\mathrm{mm} / \mathrm{h})$ & $21(18.3-41)$ & $50(23.5-16.5)$ & $30.9 \pm 17.6$ & 0.209 \\
\hline \multicolumn{5}{|l|}{ Medication history } \\
\hline Recent corticosteroid usage ${ }^{e}$ & $1(16.7 \%)$ & $5(15.6 \%)$ & 0 & 0.335 \\
\hline Recent antibiotic usage $\mathrm{e}^{\mathrm{e}}$ & $6(100 \%)$ & 31 (96.9\%) & $12(92.3 \%)$ & 0.611 \\
\hline Quinolones at bronchoscopy & $4(66.7 \%)$ & $21(65.6 \%)$ & $6(46.2 \%)$ & 0.484 \\
\hline
\end{tabular}


Table 3 Demographical and clinical features of all subjects in three lipid clusters (Continued)

\begin{tabular}{|c|c|c|c|c|}
\hline & $\begin{array}{l}\text { LClus1 } \\
(n=6)\end{array}$ & $\begin{array}{l}\text { LClus2 } \\
(n=74)\end{array}$ & $\begin{array}{l}\text { LClus3 } \\
(n=40)\end{array}$ & $p$-value \\
\hline Macrolides at bronchoscopy & $1(16.7 \%)$ & $3(9.4 \%)$ & $4(30.8 \%)$ & 0.206 \\
\hline$\beta$-lactams at bronchoscopy & $1(16.7 \%)$ & $16(50.0 \%)$ & $6(46.2 \%)$ & 0.419 \\
\hline Carbapenems at bronchoscopy & $4(66.7 \%)$ & $6(18.8 \%)$ & 0 & $0.005^{\mathrm{a}, \mathrm{b}}$ \\
\hline Vancomycin /linezolid at bronchoscopy & $2(33.3 \%)$ & $2(6.3 \%)$ & 0 & 0.073 \\
\hline \multicolumn{5}{|l|}{ Detected pathogen } \\
\hline Bacteria & $2(33.3 \%)$ & $3(9.1 \%)$ & 0 & 0.262 \\
\hline Atypical & $1(16.7 \%)$ & $10(30.3 \%)$ & $3(23.1 \%)$ & 0.737 \\
\hline Virus & $2(33.3 \%)$ & $11(33.3 \%)$ & $4(30.8 \%)$ & 0.828 \\
\hline Fungus & 0 & $3(9.1 \%)$ & $1(7.7 \%)$ & 0.836 \\
\hline Unknown & 2 & 12 & 7 & \\
\hline \multicolumn{5}{|l|}{ Complications \& Outcome } \\
\hline Hypoxemia & $6(100 \%)$ & $13(39.4 \%)$ & $3(23.1 \%)$ & $0.005^{\mathrm{a}, \mathrm{b}}$ \\
\hline IPPV & $3(50 \%)$ & $5(15.2 \%)$ & 0 & $0.022^{b}$ \\
\hline AKI & $2(33.3 \%)$ & $2(6.1 \%)$ & 0 & 0.07 \\
\hline 30-day mortality & $1(16.7 \%)$ & $5(15.2 \%)$ & 0 & 0.333 \\
\hline LOS (days) & $25.0 \pm 22.3$ & $13.4 \pm 6.5$ & $10.5 \pm 3.4$ & 0.092 \\
\hline
\end{tabular}

Data are reported as $\mathrm{n}(\%)$ for categorical data, mean $( \pm \mathrm{SD})$ for parametrically distributed data, or median (interquartile range) for nonparametrically distributed data. Statistically significant differences in variables amongst three groups are calculated using one-way ANOVA with post-hoc Turkey HSD test or Kruskal-Wallis $\mathrm{H}$ test for continuous data; and Fisher's exact test with a Bonferroni correction for categorical data. ${ }^{a}$ statistically significance exists between LClus1 and LClus2; ${ }^{b}$ statistically significance exists between LClus1 and LClus3; ${ }^{c}$ statistically significance exists between LClus2 and LClus3; ${ }^{d}$ Sample size is different than above (namely CAP patients only): LClus1, $n=6$, LClus2, $n=33$, LClus3, $n=13$; ${ }^{\mathrm{e}}$ Recent usage is defined as use of antibiotics or corticosteroids $<2$ weeks before admission Abbreviations: $B U N$ blood urea nitrogen, $C r$ creatinine, $A L T$ alanine transaminase, $A S T$ aspartate aminotransferase, $C K$ creatine kinase, $A L B$ albumin, $T C$ total cholesterol, $T G$ total triglyceride, WBC white blood cell, $N L R$ neutrophil to lymphocyte ratio, $B A L F$ bronchoalveolar lavage, $P M N$ polymorphonuclear leukocyte, $P C T$ procalcitonin, CRP C-reactive protein, ESR erythrocyte sedimentation rate, IPPV invasive positive pressure ventilation, $A K I$ acute kidney injury, LOS length of hospital stay

increased infiltration by macrophage and PMNs, respectively, which accompany local points of tissue inflammation, and thus may serve as potentially useful starting points for development of targeted therapeutics for CAP infection.

Our data showed that patients in different lipid clusters exhibited significantly different degrees of PMNs infiltrations. PMNs and macrophages are major phagocytes that play crucial roles in inflammation, the first line of defense against invaders. Activated tissue macrophages will drive inflammation by recruiting neutrophils and other leukocytes [23]. However, excessive infiltration by PMNs can also result in tissue damage. Furthermore, increases in tissue PMNs can be used as indicators of the degree of local inflammation. The high- (LClus1) and the medium- (LClus2) inflammatory response groups had inversely correlated lipid profiles in comparison to the low response group (LClus3). LClus1, high in PMNs, was characterized by abundant phospholipids (mostly PC and PE species), likely indicating damaged tissue from excessive and destructive lung inflammation, given that phospholipids are major components of all cell membranes.

However, it remains unclear if the prevalent lipids in LCLus1 and LCLus2 are responsible for the elevated inflammation, or if; conversely, the $\mathrm{PC}$ and $\mathrm{PE}$ phospholipids are produced by inflammation-induced tissue damage. Tisoncik et al. [24] reported significant abundant phospholipids (PC and PE species) in bronchial epithelial cells of ferrets in response to influenza virus infection. They speculate that the lipid mediators derived from phospholipid arachidonic acid (FA 20:4) reservoirs may contribute to tissue damage during pandemic H1N1 influenza virus infection. Our finding that PE $18: 1 \mathrm{p} / 20: 4$ is positively correlated with PMN percentages in BALF may support their hypothesis. The 20:4 side-chain in PE 18:1p/ 20:4 can be cleaved to form arachidonic acid, the precursor to eicosanoids converted by the cyclooxygenase- 2 (COX-2) enzyme. Increased production of arachidonic acid-derived pro-inflammatory prostaglandin and leukotriene levels [25] can induce PMN infiltration [26, 27], enhance inflammatory responses, and finally lead to tissue damage. In addition, although sphingolipid signal transduction pathways have been known to play an important role in the regulation of growth and survival pathways in macrophages [28], the exact role of SM (d34:1) still requires future research.

Our data shows that fatty acids are notably involved in CAP. First, they are the most abundant lipids detected in the BALF lipidome in our study. Furthermore, BALF levels of unsaturated FA (including MUFA and PUFA) are significantly elevated in CAP and the high- 
Table 4 Comparisons of lipid subclasses amongst the three clusters

\begin{tabular}{|c|c|c|c|c|c|c|}
\hline \multirow[t]{2}{*}{ Lipid class } & \multirow{2}{*}{$\begin{array}{l}\text { Lipid } \\
\text { Sub- } \\
\text { Class }\end{array}$} & \multicolumn{3}{|l|}{ Fold change } & \multirow{2}{*}{$\begin{array}{l}\text { Kruskal- } \\
\text { Wallis } \\
\text { adjusted } \\
\text { p-value }\end{array}$} & \multirow[t]{2}{*}{ Tendency } \\
\hline & & LClus1/LClus3 & LClus2/LClus3 & LClus1/LClus2 & & \\
\hline Acyl carnitines & $\mathrm{AcCa}$ & 0.67 & $0.31^{* * *}$ & 2.18 & $<0.0005$ & \\
\hline \multirow[t]{3}{*}{ Fatty acids } & SFA & 0.79 & $1.08^{* * *}$ & $0.73^{* * *}$ & $<0.0005$ & Up in LClus2 \\
\hline & MUFA & $3.59^{* * *}$ & 1.03 & $3.48^{* *}$ & $<0.0005$ & Up in LClus1 \\
\hline & PUFA & $3.66^{* *}$ & 0.84 & $4.34^{* * *}$ & $<0.0005$ & Up in LClus1 \\
\hline \multirow[t]{6}{*}{ Sphingolipids } & Cer & 0.54 & 0.81 & 0.66 & 0.117 & \\
\hline & CerG1 & 1.10 & $0.52^{* * *}$ & 2.11 & $<0.0005$ & \\
\hline & CerG2 & $8.95^{*}$ & 4.58 & $1.95^{* *}$ & 0.009 & Up in LClus1 \\
\hline & GM3 & 1.00 & $0.23^{* * *}$ & $4.46^{* * *}$ & $<0.0005$ & Down in LClus2 \\
\hline & SM & 1.37 & $0.49^{* * *}$ & $2.81^{* * * *}$ & $<0.0005$ & Down in LClus2 \\
\hline & So & 1.37 & $0.49^{*}$ & 2.81 & 0.013 & \\
\hline \multirow[t]{2}{*}{ Neutral lipids } & DG & 1.19 & 22.90 & 0.05 & 0.136 & \\
\hline & TG & 0.82 & $1.23^{* * *}$ & $0.66^{* *}$ & $<0.0005$ & Up in LClus2 \\
\hline \multirow[t]{8}{*}{ Phospholipids } & $P C$ & 1.85 & $0.40^{* * *}$ & $4.67^{* * *}$ & $<0.0005$ & Down in LClus2 \\
\hline & $P E$ & 2.88 & $0.68^{* * * *}$ & $4.27^{* * * *}$ & $<0.0005$ & Down in LClus2 \\
\hline & $P G$ & 0.95 & $0.31^{* * *}$ & $3.09^{*}$ & $<0.0005$ & Down in LClus2 \\
\hline & $\mathrm{Pl}$ & 1.95 & $0.39^{* * * *}$ & $4.95^{* * *}$ & $<0.0005$ & Down in LClus2 \\
\hline & PS & 1.84 & $0.61^{* * *}$ & $3.01^{*}$ & $<0.0005$ & Down in LClus2 \\
\hline & LPC & 0.52 & $0.43^{* * * *}$ & 1.20 & $<0.0005$ & \\
\hline & LPE & 0.45 & $0.45^{* * *}$ & 0.99 & $<0.0005$ & \\
\hline & LPG & 0.79 & $0.31^{* * *}$ & 2.53 & $<0.0005$ & \\
\hline
\end{tabular}

Tendency is indicated only when the cluster is differed from all the other clusters. The ${ }^{*}$ depicts a statistically significant difference. ${ }^{*} p<0.05 ;{ }^{* *} p<0.01 ;{ }^{* * *} p<$ 0.001

inflammatory response group (LClus1); while levels of SFA are increased in the medium-inflammatory response group (LClus2). Third, several MUFAs (FA 16:1, FA 18:1, and FA 20:1) could be effective markers for SCAP. Moreover, FA 18:3, an n-3 PUFA, is notably elevated in the high-inflammatory response group (LClus1).

Previous studies have revealed that both levels and compositions of FAs are associated with inflammation [29].
Generally, SFAs are considered as pro-inflammatory lipid mediators as they induce the inflammation by mimicking the actions of lipopolysaccharide (LPS) [30], activating the NLRP3 inflammasome [31], and inducing NFKB signaling [32], etc. In contrast, PUFAs are commonly considered as anti-inflammatory lipid mediators as they can inhibit inflammasome activation [33] and can inhibit endothelial cell activation following exposure to LPS [34]. In addition,


Fig. 5 Two lipid species show significantly correlations with BALF cellular components. a SM (d34:1) is inversely correlated to macrophage percentages of BALF, adjusted $r=-0.462, p<0.0001$. b PE (18:1 $/ 20: 4)$ is positively correlated with PMN percentages of BALF, spearman rank $r=0.3639, p<0.0001$. Red line, the fitted regression line. Areas within the grey lines, the $95 \%$ confidence intervals 
specialized pro-resolving lipid (SPM) mediators (the resolvins and the protectins/neuroprotectins) derived from n-3 PUFA [35] reveal their role as anti- and pro-resolving inflammation as well as enhancing microbial clearance [8]. Unexpectedly, our data suggested the opposite tendencies of pro- and anti-inflammatory lipid alternations in either CAP patients or patients in LClus1. Recently Sun and colleagues report that same pattern of accumulation of serum palmitic acid (FA 16:0) during H7N9 pneumonia. The levels of palmitic acid decreased while the clinical conditions became more severe, and increased as the disease was ameliorated [36]. Schmidt et al. also found that PUFA increased approximately 3-fold in BALF of adult respiratory disease syndrome (ARDS) patients [37]. In light of our own data, which agrees with the findings of Schmidt and Sun, we are compelled to reconsider the pro- and anti-inflammatory designations assigned to bioactive lipids, since their proposed activity is not supported by our HPLC-MS data in CAP patients. We speculate that the role of bioactive lipids, such as PUFAs in mitigating inflammation, is context dependent and may be influenced by other factors that fall outside the scope of this study.

TG and SM classes, the top 2 and the top 3 lipid sub-classes of the total BALF lipidome, respectively, show no difference between CAP and controls, and no difference between the LClus1 high-inflammatory response group and the LClus3 low-inflammatory response group. Previous studies have reported hypertriglyceridemia during infection, and different types of infection (bacterial, viral, or fungal) result in similar effects on triglyceride metabolism [38-41]. Infection-associated hypertriglyceridemia is induced via increased hepatic lipoprotein production and/or decreased lipoprotein catabolism [42]. However, some clinical studies came to the opposite conclusion, partially supporting our observations, in that lower or no significantly changes in triglyceride levels were observed in critically ill and severely infected patients $[43,44]$. Moreover, Kaysen and colleagues reported an inverse association between serum triglyceride levels and all-cause mortality (HR: 0.93, 95\% CI: 0.90-0.96) [45].

Likewise, inflammation induces SM hydrolysis, tending to decrease the SM mass and lead to ceramide accumulation [46]. Nonetheless, the enhanced de novo sphingolipid biosynthesis during inflammation can lead to the formation of ceramide and subsequent the formation of sphingomyelin [47]. Which might be the most plausible explanation for the sustained SM levels in LClus1.

Together with previous studies, our work suggests that distinct lipid profiles repeat over numbers of patients, accompanied by different airway inflammatory status and disease severity, although host-lipidome is considered uniformly detrimental to patients with the same disease. Whether the observed lipidome changes are a cause or a consequence of the development of pneumonia or merely coincide with disease status remains a question. Larger cohorts of patients are necessary to sufficiently power studies examining lipid compositions and quantifications, their inflammatory status, and clinical implications. Further longitudinal studies would advance understanding of temporal changes in lipids prior to disease onset.

\section{Conclusion}

The global profiling analysis of CAP uncovered complex lipidomic responses to infection, with the levels of mediators involved in both pro- and anti-inflammatory processes. Thus arguing for the potential need to tailor therapy on the specific disturbed lipid profiles and related inflammatory status exhibited by the subjects.

\section{Additional files}

Additional file 1: Supplementary Methods. (DOCX 13 kb)

Additional file 2: Tables S1. Summary of unique lipid species, by class, identified using LC-MS. Table S2. Thirty-three lipid species differentiated SCAP from controls. Table S3. Forty-one lipid species differed amongst three lipid clusters (LClus). Table S4. Correlation matrix of differential lipids of clusters and phagocyte percentages of BALF. (ZIP $123 \mathrm{~kb}$ )

Additional file 3: Figure S1. Receiver operating characteristics (ROC) curves for FA (16:1), FA (18:1), FA (20:1), and FA (24:0) show the abilities to discriminate SCAP from NSCAP. Figure S2. Result of the elbow method to determine optimum number of clusters ( $k=3$ ). (ZIP $287 \mathrm{~kb}$ )

\section{Abbreviations}

AcCa: Acylcarnitine; Cer: Ceramide; CerG1: Glucosylceramide; ChE: Cholesterol ester; DG: Diglyceride; FA: Fatty acid; GM3: Monosialotetrahexosylganglioside3; LacCer: Lactosylceramide; LPC: Lysophosphatidylcholine;

LPE: Lysophosphatidylethanolamine; LPG: Lysophosphatidylglycerol; PC: Phosphatidylcholine; PE: Phosphatidylethanolamine;

PG: Phosphatidylglycerol; PI: Phosphatidylinositol; PS: Phosphatidylserine; SM: Sphingomyelin; So: Sphingosine; TG: Triglyceride

\section{Acknowledgements}

The authors wish to thank staff members of the cooperating hospitals (Department of Pulmonary and Critical Care Medicine, Shanghai Pulmonary Hospital, Shanghai, China; Department of Pulmonary and Critical Care Medicine, West China Hospital, Sichuan, China; and Department of Pulmonary and Critical Care Medicine, Second Hospital of Jilin University, Jilin, China) for assistance with samples and clinical data collection. They are also grateful to the Metabolomics Facility at the Technology Center for Protein Sciences, Tsinghua University for technical support.

\section{Funding}

The work was funded by the Ministry of Science and Technology of China (2016YFC0903800 and 2017ZX10103004-006) and the National Natural Science Foundation of China (81500005).

Availability of data and materials

The authors confirm that the data supporting the findings of this study are available within the article and/or its supplementary materials.

Authors' contributions

Conception and design: $Y Z, K Y$ and $Z G$; Acquisition, analysis or interpretation of data: $Y Z, P N, Q L, Y H, X L, Y C, X Y$, and $X W$; Drafting the manuscript: $Y Z$; Statistical analysis: $Y Z, P N, Q L$, and $Y H$; Administrative, technical or material 
support: PN and $X \mathrm{~L} ;$ All authors reviewed, revised and approved the manuscript for submission; Study supervision: YK and ZG.

\section{Ethics approval and consent to participate}

This research was approved by the Ethical Committee of PKUPH and was conducted according to the principles expressed in the Declaration of Helsinki. All subjects provided informed consent prior to the collection of any data.

\section{Consent for publication}

All the authors have read and approved the final manuscript and the manuscript is submitted solely to Respiratory Research.

\section{Competing interests}

The authors declare that they have no competing interests.

\section{Publisher's Note}

Springer Nature remains neutral with regard to jurisdictional claims in published maps and institutional affiliations.

\section{Author details}

'Department of Pulmonary and Critical Care, Peking University People's Hospital, Beijing, China. ${ }^{2}$ Department of Pulmonary and Critical Care, the Second Affiliated Hospital of Xi'an Jiaotong University, Xi'an, China. ${ }^{3}$ National Protein Science Technology Center, Tsinghua University, Beijing, China. ${ }^{4}$ Department of Pulmonary and Critical Care, Fujian Provincial Hospital, Fuzhou, China. ${ }^{5}$ Department of Pulmonary and Critical Care, Union Hospital, Tongji Medical College, Huazhong University of Science and Technology, Wuhan, China. ${ }^{6}$ CAS Key Laboratory of Genome Sciences and Information, Beijing Institute of Genomics, Chinese Academy of Sciences, Beijing, China.

\section{Received: 25 January 2019 Accepted: 19 March 2019}

\section{Published online: 02 May 2019}

\section{References}

1. Global, regional, and national age-sex specific mortality for 264 causes of death, 1980-2016: a systematic analysis for the Global Burden of Disease Study 2016. Lancet 2017, 390:1151-1210.

2. Ramirez JA, Wiemken TL, Peyrani P, Arnold FW, Kelley R, Mattingly WA Nakamatsu R, Pena S, Guinn BE, Furmanek SP, et al. Adults hospitalized with pneumonia in the United States: incidence, epidemiology, and mortality. Clin Infect Dis. 2017;65:1806-12.

3. National Health and Family Planning Commission C: China Health and Family Planning Statistics Yearbook (2013). Available from: http://www. nhfpc.gov.cn/htmlfiles/zwgkzt/ptjnj/year2013/index2013.html.

4. Jain S, Self WH, Wunderink RG, Fakhran S, Balk R, Bramley AM, Reed C, Grijalva CG, Anderson EJ, Courtney DM, et al. Community-acquired pneumonia requiring hospitalization among U.S. adults. N Engl J Med. 2015; 373:415-27.

5. World Population Prospects: The 2017 Revision | Multimedia Library - United Nations Department of Economic and Social Affairs. Available online: https://www.un.org/development/desa/publications/world-populationprospects-the-2017-revision.html.

6. Hannun YA, Obeid LM. Principles of bioactive lipid signalling: lessons from sphingolipids. Nat Rev Mol Cell Biol. 2008;9:139.

7. Serhan CN, Chiang N, Van Dyke TE. Resolving inflammation: dual antiinflammatory and pro-resolution lipid mediators. Nat Rev Immunol. 2008;8:349-61

8. Serhan CN. Pro-resolving lipid mediators are leads for resolution physiology. Nature. 2014;510:92-101.

9. Duvall MG, Bruggemann TR, Levy BD. Bronchoprotective mechanisms for specialized pro-resolving mediators in the resolution of lung inflammation. Mol Asp Med. 2017:58:44-56.

10. Ning $P$, Zheng $Y$, Luo Q, Liu X, Kang $Y$, Zhang $Y$, Zhang $R, X u Y$, Yang $D, X$ W. Metabolic profiles in community-acquired pneumonia: developing assessment tools for disease severity. Crit Care. 2018:22:130

11. Mandell LA, Wunderink RG, Anzueto A, Bartlett JG, Campbell GD, Dean NC, Dowell SF, File TM Jr, Musher DM, Niederman MS. Infectious Diseases Society of America/American Thoracic Society consensus guidelines on the management of community-acquired pneumonia in adults. Clin Infect Dis. 2007:44:S27-72
12. Evans CR, Karnovsky A, Kovach MA, Standiford TJ, Burant CF, Stringer KA Untargeted LC-MS metabolomics of Bronchoalveolar lavage fluid differentiates acute respiratory distress syndrome from health. J Proteome Res. 2014;13:640-9.

13. Chen S, Hoene M, Li J, Li Y, Zhao X, Haring HU, Schleicher ED, Weigert C, XU $\mathrm{G}$, Lehmann R. Simultaneous extraction of metabolome and lipidome with methyl tert-butyl ether from a single small tissue sample for ultra-high performance liquid chromatography/mass spectrometry. J Chromatogr A. 2013:1298:9-16

14. Tang H, Wang X, Xu L, Ran X, Li X, Chen L, Zhao X, Deng H, Liu X. Establishment of local searching methods for orbitrap-based high throughput metabolomics analysis. Talanta. 2016;156:163-71.

15. Bijlsma S, Bobeldijk I, Verheij ER, Ramaker R, Kochhar S, Macdonald IA, Van $\mathrm{OB}$, Smilde AK. Large-scale human metabolomics studies: a strategy for data (pre-) processing and validation. Anal Chem. 2006;78:567.

16. Yang J, Zhao X, Lu X, Lin X, XU G. A data preprocessing strategy for metabolomics to reduce the mask effect in data analysis. Front Mol Biosci. 2015;2:4.

17. Kirwan JA, Broadhurst DI, Davidson RL, Viant MR. Erratum to: Characterising and correcting batch variation in an automated direct infusion mass spectrometry (DIMS) metabolomics workflow. Anal Bioanal Chem. 2014:406:6075-6.

18. van den Berg RA, Hoefsloot HCJ, Westerhuis JA, Smilde AK, van der Werf MJ. Centering, scaling, and transformations: improving the biological information content of metabolomics data. BMC Genomics. 2006;7:142.

19. Chong J, Soufan O, Li C, Caraus I, Li S, Bourque G, Wishart DS, Xia J. MetaboAnalyst 4.0: towards more transparent and integrative metabolomics analysis. Nucleic Acids Res. 2018;46:W486-94.

20. Steinhaus H. Sur la division des corp materiels en parties. Bull Acad Polon Sci. 1956:1:801.

21. Ketchen DJ, Shook CL. The application of cluster analysis in strategic management research: an analysis and critique. Strateg Manag J. 1996;17:441-58

22. Charrad M, Ghazzali N, Boiteau V, Niknafs A, Charrad MM. Package 'nbclust. J Stat Softw. 2014;61:1-36

23. Davies LC, Jenkins SJ, Allen JE, Taylor PR. Tissue-resident macrophages. Nat Immunol. 2013;14:986-95.

24. Tisoncik-Go J, Gasper DJ, Kyle JE, Eisfeld AJ, Selinger C, Hatta M, Morrison J, Korth MJ, Zink EM, Kim Y-M. Integrated omics analysis of pathogenic host responses during pandemic H1N1 influenza virus infection: the crucial role of lipid metabolism. Cell Host Microbe. 2016;19:254-66.

25. Dennis EA, Norris PC. Eicosanoid storm in infection and inflammation. Nat Rev Immunol. 2015:15:511-23.

26. Lemos HP, Grespan R, Vieira SM, Cunha TM, Verri WA, Fernandes KSS, Souto FO, McInnes IB, Ferreira SH, Liew FY, Cunha FQ. Prostaglandin mediates IL23/IL-17-induced neutrophil migration in inflammation by inhibiting IL-12 and IFNy production. Proc Natl Acad Sci. 2009;106:5954-9.

27. Wright HL, Moots RJ, Bucknall RC, Edwards SW. Neutrophil function in inflammation and inflammatory diseases. Rheumatology. 2010:49:1618-31.

28. Gómez-Muñoz A, Kong J, Salh B, Steinbrecher UP. Sphingosine-1-phosphate inhibits acid sphingomyelinase and blocks apoptosis in macrophages. FEBS Lett. 2003;539:56-60

29. Fritsche KL. The science of fatty acids and inflammation. Adv Nutr (Bethesda, Md). 2015;6:293S-301S.

30. Glass CK, Olefsky JM. Inflammation and lipid signaling in the etiology of insulin resistance. Cell Metab. 2012;15:635-45.

31. Robblee MM, Kim CC, Porter Abate J, Valdearcos M, Sandlund KL, Shenoy MK, Volmer R, Iwawaki T, Koliwad SK. Saturated fatty acids engage an IRE1alpha-dependent pathway to activate the NLRP3 Inflammasome in myeloid cells. Cell Rep. 2016;14:2611-23.

32. Suganami T, Tanimoto-Koyama K, Nishida J, Itoh M, Yuan X, Mizuarai S, Kotani H, Yamaoka S, Miyake K, Aoe S, et al. Role of the toll-like receptor 4/ NF-kappaB pathway in saturated fatty acid-induced inflammatory changes in the interaction between adipocytes and macrophages. Arterioscler Thromb Vasc Biol. 2007;27:84-91.

33. Yan Y, Jiang W, Spinetti T, Tardivel A, Castillo R, Bourquin C, Guarda G, Tian Z, Tschopp J, Zhou R. Omega-3 fatty acids prevent inflammation and metabolic disorder through inhibition of NLRP3 inflammasome activation. Immunity. 2013;38:1154-63.

34. Yamada H, Yoshida M, Nakano Y, Suganami T, Satoh N, Mita T, Azuma K, Itoh M, Yamamoto $Y$, Kamei $Y$, et al. In vivo and in vitro inhibition of 
monocyte adhesion to endothelial cells and endothelial adhesion molecules by eicosapentaenoic acid. Arterioscler Thromb Vasc Biol. 2008;28:2173-9.

35. Whittington RA, Planel E, Terrando N. Impaired resolution of inflammation in Alzheimer's disease: a review. Front Immunol. 2017;8:1464.

36. Sun X, Song L, Feng S, Li L, Yu H, Wang Q, Wang X, Hou Z, Li X, Li Y, et al. Fatty acid metabolism is associated with disease severity after H7N9 infection. EBioMedicine. 2018;33:218-29.

37. Schmidt R, Luboeinski T, Markart P, Ruppert C, Daum C, Grimminger F, Seeger W, Gunther A. Alveolar antioxidant status in patients with acute respiratory distress syndrome. Eur Respir J. 2004;24:994-9.

38. Gallin Jl, Kaye D, O'Leary WM. Serum lipids in infection. N Engl J Med. 1969;281:1081-6.

39. Khovidhunkit W, Memon RA, Feingold KR, Grunfeld C. Infection and inflammation-induced Proatherogenic changes of lipoproteins. J Infect Dis. 2000;181:S462-72.

40. Kerttula Y, Weber T. Serum lipids in pneumonia of different aetiology. Ann Clin Res. 1988;20:184-8.

41. Tam VC. Lipidomic profiling of bioactive lipids by mass spectrometry during microbial infections. Semin Immunol. 2013;25:240-8.

42. Feingold KR, Staprans I, Memon R, Moser A, Shigenaga J, Doerrler W, Dinarello C, Grunfeld C. Endotoxin rapidly induces changes in lipid metabolism that produce hypertriglyceridemia: low doses stimulate hepatic triglyceride production while high doses inhibit clearance. J Lipid Res. 1992; 33:1765-76.

43. Gordon BR, Parker TS, Levine DM, Saal SD, Wang JC, Sloan BJ, Barie PS, Rubin AL. Low lipid concentrations in critical illness: implications for preventing and treating endotoxemia. Crit Care Med. 1996;24:584-9.

44. Nassaji M, Ghorbani R. Plasma lipid levels in patients with acute bacterial infections. Turkish J Med Sci. 2012;42:465-9.

45. Kaysen G, Ye X, Raimann JG, Wang Y, Topping A, Usvyat LA, Stuard S, Canaud B, van der Sande FM, Kooman JP: Lipid levels are inversely associated with infectious and all-cause mortality: international MONDO study results. J Lipid Res 2018:JIr. P084277.

46. Ryan AJ, McCoy DM, McGowan SE, Salome RG, Mallampalli RK. Alveolar sphingolipids generated in response to TNF-a modifies surfactant biophysical activity. J Appl Physiol. 2003:94:253-8.

47. Maceyka M, Spiegel S. Sphingolipid metabolites in inflammatory disease. Nature. 2014:510:58

Ready to submit your research? Choose BMC and benefit from:

- fast, convenient online submission

- thorough peer review by experienced researchers in your field

- rapid publication on acceptance

- support for research data, including large and complex data types

- gold Open Access which fosters wider collaboration and increased citations

- maximum visibility for your research: over $100 \mathrm{M}$ website views per year

At BMC, research is always in progress.

Learn more biomedcentral.com/submissions 